\title{
IMAGENS DA FÉ NA ALDEIA DOS ORIXÁS
}

ROSILEIDE DA SILVA ${ }^{1}$

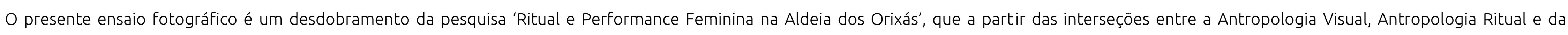

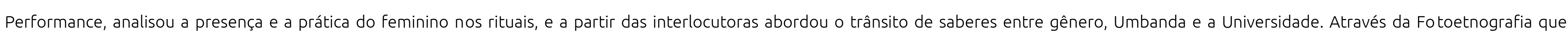

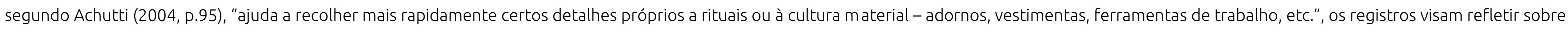

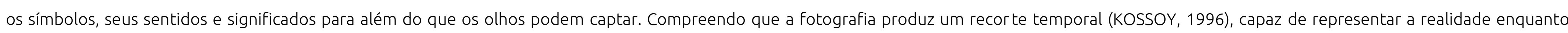

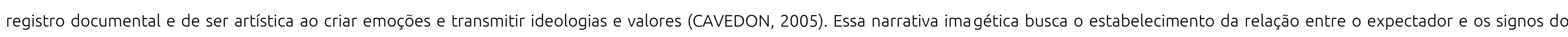
sagrado, para uma interpretação sobre as particularidades captadas durante os rituais. 

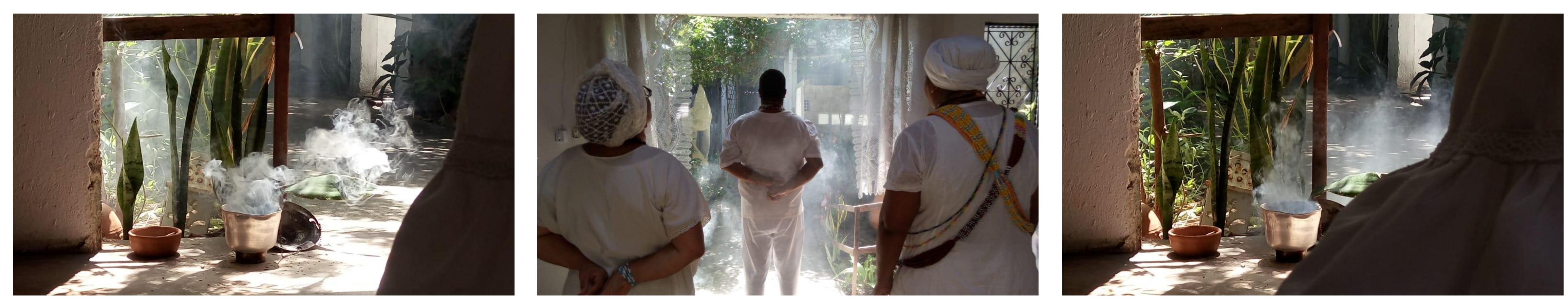

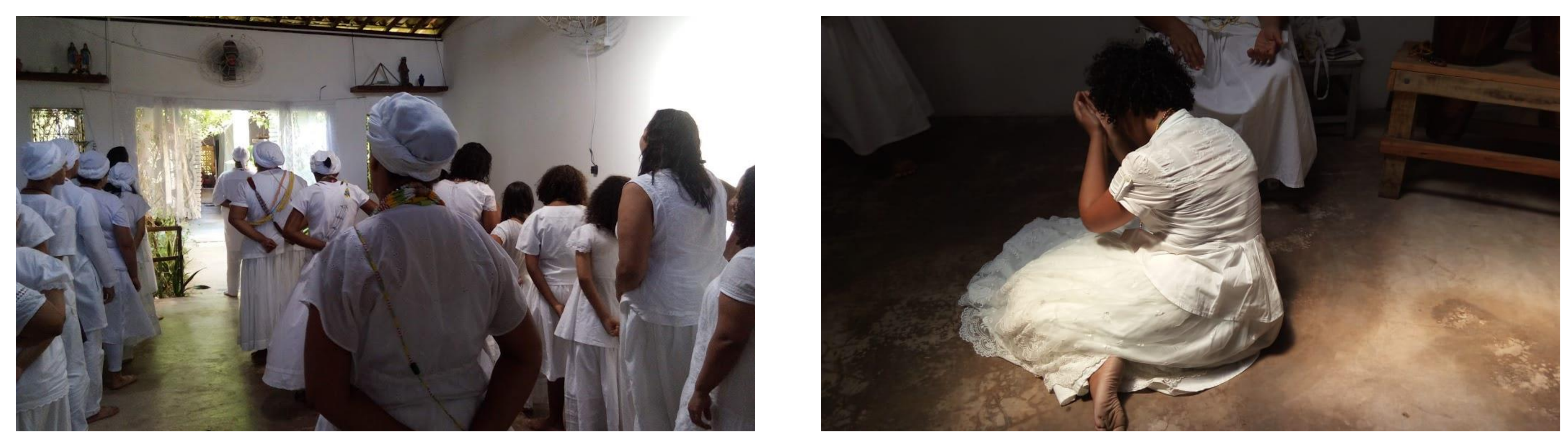

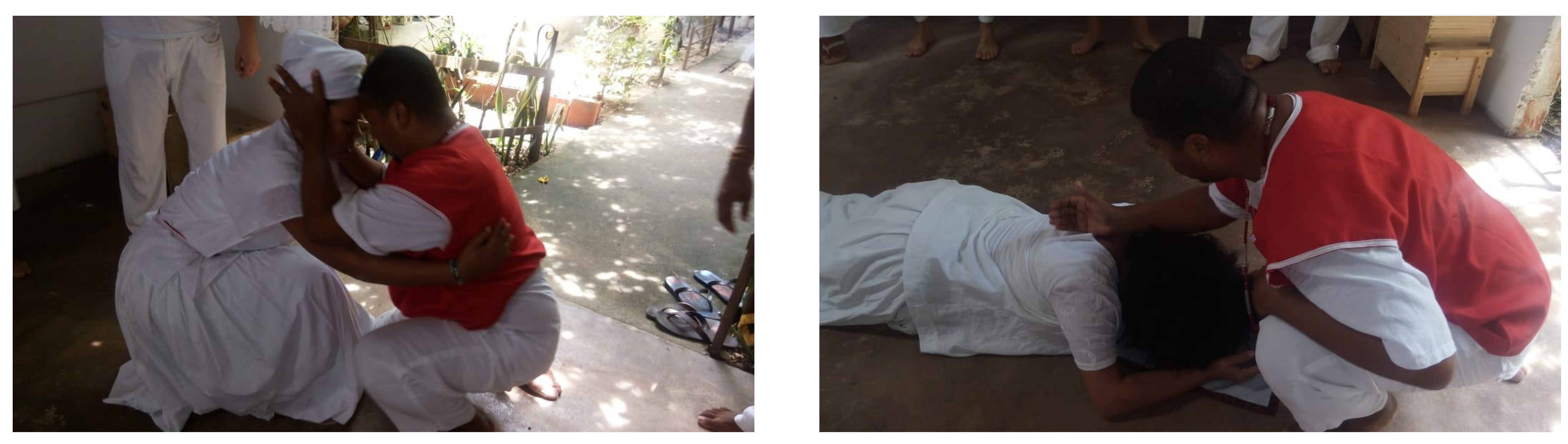

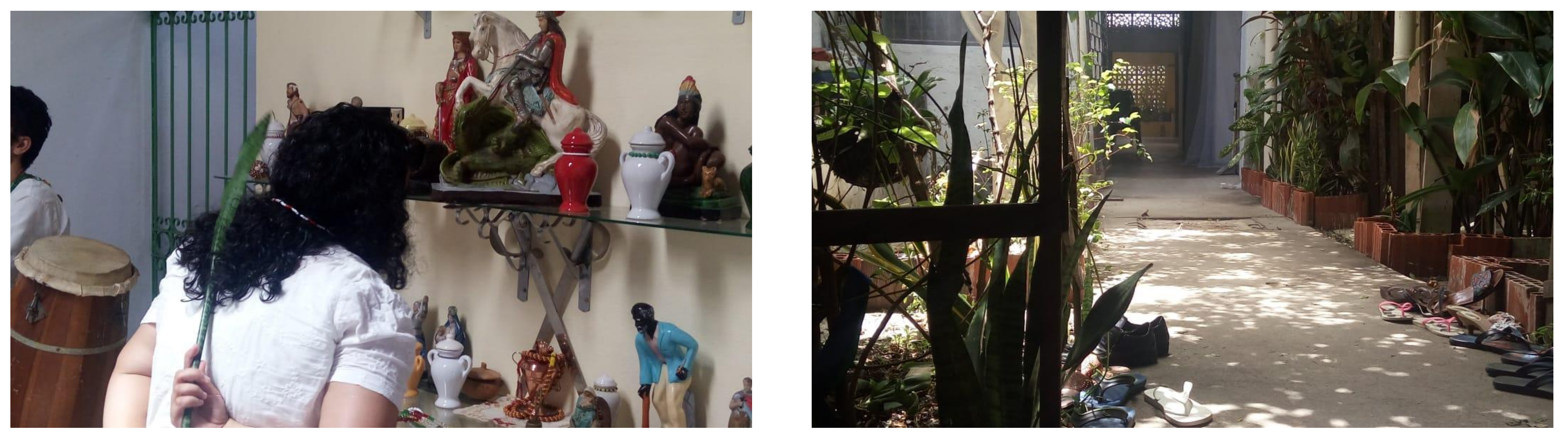
ACHUTTI, Luiz Eduardo Robinson. Fotoetnografia da Biblioteca Jardim. Porto Alegre: Editora da UFRGS/Tomo Editorial, 2004. CAVEDON, Neusa Rolita. "Fotoetnografia: a união da fotografia com a etnografia no descortinamento dos não ditos organizacionais". Organ. Soc., Salvador , v. 12, n. 35, p. 13-27, Dec. 2005. KOSSOY, Boris. A fotografia como fonte histórica. introdução à pesquisa e interpretação das imagens do passado. São Paulo, Museu da Ind. Com. e Tecnologia de São Paulo - SICCT, 1980. p. 29.

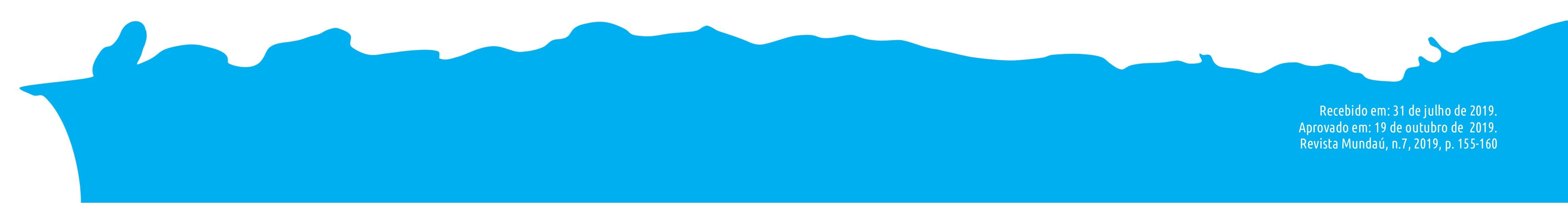

